\title{
ARELA/RS - Associação Regional de Esclerose Lateral Amiotrófica do Rio Grande do Sul
}

\section{Leila Denise Neto Ortiz}

Presidente Eleita da Associação Regional de ELA do Estado do Rio Grande do Sul

A ARELA foi fundada dia 30 de outubro de 2005 em Gramado, com o objetivo de ajudar o portador de Esclerose Lateral Amiotrófica, seus familiares e cuidadores, em todas as fases da doença. A associação é filiada à ABRELA - a Associação Brasileira de Esclerose Lateral Amiotrófica.

Para se construir uma associação que consiga levar adiante tais objetivos, deve-se ter em mente o seu arcabouço jurídico e estrutural. A ARELA elaborou um estatuto no ano seguinte e formou sua diretoria no mesmo momento, com cargos que visavam a distribuição de tarefas e coordenação. Em 2008 estabelecemos uma localização física e registro em Pessoa Jurídica, importante para podermos de maneira legal receber financiamentos e doações.

Desde o início de nossa empreitada realizamos simpósios direcionados à portadores, familiares e profissionais da saúde, e temos aumentado progressivamente o número de associados e novos apoiadores.

O nosso modelo tem por prioridade o portador e o familiar, e atingimos nossos objetivos de diferentes formas: desde levando informação e orientação tanto para os acima citados quanto à profissionais de saúde, indo à aquisição de equipamentos necessários para o suporte, até o cadastro e educação continuada dos profissionais afiliados que se doam para nossa causa. 


\section{SIMPÓSIO BRASILEIRO DE DNM/ELA}

São passos importantes para futuras associações regionais de outros estados a parceria com a ABRELA, o cadastro de portadores e profissionais da saúde e a organização de um evento para marcar a fundação da associação (ou assembléia), o cuidado com as diretrizes através de um estatuto e a determinação de uma diretoria. 